\title{
Article
}

\section{Understanding nature sports: A participant centred perspective and its implications for the design and facilitating of learning and performance}

Collins, Loel and Brymer, E.

Available at http://clok.uclan.ac.uk/24194/

Collins, Loel ORCID: 0000-0002-7478-1140 and Brymer, E. (2020)

Understanding nature sports: A participant centred perspective and its implications for the design and facilitating of learning and performance. Annals of Leisure Research, 23 (1). pp. 110-125. ISSN 1174-5398

It is advisable to refer to the publisher's version if you intend to cite from the work. http://dx.doi.org/10.1080/11745398.2018.1525302

For more information about UCLan's research in this area go to http://www.uclan.ac.uk/researchgroups/ and search for <name of research Group>.

For information about Research generally at UCLan please go to http://www.uclan.ac.uk/research/

All outputs in CLoK are protected by Intellectual Property Rights law, including Copyright law. Copyright, IPR and Moral Rights for the works on this site are retained by the individual authors and/or other copyright owners. Terms and conditions for use of this material are defined in the policies page. 
Understanding Nature sports: a participant centred perspective and its implications for the design and facilitating of learning and performance

$$
\text { Loel Collins }{ }^{\mathrm{a}^{*}} \text { and Eric Brymer }{ }^{\mathrm{b}}
$$

anstitute of Coaching and Performance, University of Central Lancashire;

${ }^{b}$ Institute of Sport Physical Activity and Leisure, Leeds Beckett University, Leeds

*corresponding author: LCollins2@uclan.ac.uk 


\title{
Understanding nature sports: a participant centred perspective and its implications for learning and learning design
}

\begin{abstract}
Nature sports is a term used to describe a collection of physical activities that are frequently defined by characteristics of their environment or an inherent risk. These perspectives overlook new aspects of nature sports and motivations for participation, imposing an inaccurate perspective on the design and facilitation of learning experiences. Namely, that nature sports are undertaken by participants with an inherent need for risk. This paper presents an alternative perspective based on critiques of the traditional notions of the experience of participants which goes beyond notions of risk taking and thrill seeking. Adopting a participant focus provides insight into the constant evolution of techniques, participation, philosophies and the continuous striving for creativity and innovation. Effective learning design and facilitation in nature sports therefore demands adaptability, flexibility, cultural sensitivity, and the capacity to facilitate a participant's interaction with their environment.
\end{abstract}

(1)Keywords: Risk taking, action, adventure, learning, learning design 
Introduction

'Nature sport' has emerged as one of many terms (e.g. adventure sports, high-risk sports, action sports, outdoor sports, extreme sports to name the most popular) used to refer to a collection of physical activities that are surpassing many traditional sports in popularity (Brymer \& Schweitzer, 2017a; Pain \& Pain, 2005). Examples of such activities include kayaking, BASE (Building, Antennae, Space and Earth) jumping, skiing, climbing, walking and surfing. Additionally, the growth of adventure tourism and participation in nature sports has expanded possible participation beyond the wellresearched and established realms of outdoor education (Peacock, Brymer, Davids \& Dillon, 2017). Consequently, we take a position that reflects a leisure, tourism and participation perspective. The thread that binds the activities defined as 'nature' sports is that for the most part they are undertaken in relation to the natural environment and not bound by predetermined rules or artificially determined physical boundaries. Understanding, more fully, the nature of nature sports seems paramount if we are to help leaders, coaches and instructors meet the demands of an increasingly diverse group of participants. We suggest three possible advantages to this review (1) to challenge the theoretical perspectives that have surrounded participation in nature sports, (2) to distinguish between sub-groups within nature sports or sports more widely, and (3) to focus academic research concerns.

In this paper, we argue that the traditional risk based approach to nature sports is an oversimplification and a more comprehensive understanding of nature sports that focuses on the experience of the participant is needed to guide effective facilitation of experiences and learning. Following an outline of the traditional perspective, we investigate and critique definitions of the variety of nature sports categories such as 
action sports, adventure sports, extreme sports, lifestyle sports, and high risk sports. We, then, take an overview of current approaches to the facilitation of experiences and learning to highlight how the traditional risk focused approach has infiltrated the design and facilitation of learning experiences. Finally, we show how the notion of nature sports could be understood from a participant perspective.

\section{The typical theoretical perspective}

The typical theoretical and popular perspective on nature sport activities emphasizes risk and risk taking. Activities are defined in terms of; (1) characteristics of the physical environment where the environment is assumed to be dangerous, dynamic or uncertain,(2) personality characteristics, where participants are described as risk takers or adrenalin seekers searching for novelty and uncertainty (Rossi \& Cereati, 1993, Self, Henry, Findley, \& Reilly, 2007; Slanger \& Rudestam, 1997), (3) the socio-cultural environment where participants are presumed to create a personal identity based on fitting in with risk based counter-cultural characteristics (e.g. lifestyle sports; Wheaton, 2004).

A number of problems with the traditional approach that have a direct implication for the design and facilitation of learning and experiences in nature sports have been identified (Brymer \& Schweitzer, 2017b). For example, a risk focused perspective might assume that participants are only interested in thrills and excitement and as a consequence providers of experiences are inclined to only focus on providing opportunities for thrills and excitement. Notions of providing opportunities for enhancing health, connecting to nature and developing expertise could be ignored. Equally, the provision of learning opportunities might be primarily focused on risk management or providing the skills required to undertake greater risk focused challenges. From this perspective, learning facilitators are less likely to be interested in 
designing experiences that address a broader or more nuanced range of motivations for participation. From the risk perspective nature becomes the competitor, a battleground or playground with the sole purpose of providing a context for the participant to test capabilities (Brymer, 2009, Brymer \& Gray, 2009, 2010). An emphasis on the risk focused approach in marketing is also more likely to attract people who already wish to take risks and therefore create the potential for unfortunate mishaps; a vicious circle.

\section{The complex nature of nature sports: the traditional perspective}

Nature sports, a relatively new term coined to describe those physical activities undertaken in the presence of nature or while being immersed in nature (Melo \& Gomes, 2017, Krien, 2014), are fast becoming the physical activity of choice across the world. Nature sports are not bound by rules, regulations or set boundaries. Nor are they easily constrained by traditional notions of 'sport' as structured, competitive activities. Equally, nature sports do not easily comply with a modernist view of sport that originates in western Christian philosophies. Instead, nature sports are perhaps best allied with the original appreciation of sport as pastime and recreation (Immonen et al., 2017) and a post-modernist perspective on sport as multi-faceted and including dimensions of self-development, recreation, social, historical, political and cultural discourses, and personal interpretation.

Perhaps because of these broad characterisations we know little about the complexities of nature sports. Developing an understanding of nature sports seems essential for business operators, learning designers and facilitators, and policymakers. Nature sport activities have become part of the tourism industry, the health industry, recreation and leisure industry, and remain an important aspect of the education sector. More recently, adapted versions of nature sports have infiltrated the traditional sporting sector (see 'sportification', Crump, 1991). For the most part, attempts to define nature sports have 
been constrained by the context. However, mountain biking, climbing, snowboarding or surfing in an Olympic context where boundaries are constrained and regulations imposed might be different to mountain biking, climbing, snowboarding or surfing when undertaken as part of a health intervention or as a leisure pursuit or as a tourism activity. Indeed, the various terms used to describe seemingly similar activities seems to reinforce this perspective and make definitions challenging. While these different types of nature sports have some distinct, differentiating and unique elements, they also have common aspects that are pertinent and significant to the participant and the notion of nature sports.

In the following section we review the key features of common types of sports captured by the main terms currently used to describe the varieties of 'nature' sports. The aim of this section is to investigate similarities and differences within the varieties of nature sports to highlight the complex nature of nature sports. In this process, we attempt to clarify the features of each category and highlight the crossover between the many types of nature sports. We have been careful to filter for nuances in the literature where activities might seem similar but do not refer to nature sports. For example, literature on indoor alternatives to climbing, skiing, skydiving and sports that are mainly about competition are not considered.

\section{Extreme and high risk sports}

The terms extreme sport and high risk sport have often been used interchangeably to define activities where the likely outcome of a mismanaged mistake or accident is death (Brymer and Schweitzer, 2017a; Frühauf, Hardy, Pfoestl, Hoellen and Kopp, 2017). Examples of activities in this category that clearly involve interacting with nature include BASE jumping (including proximity flying), big wave surfing, mountaineering above the death zone (above $8000 \mathrm{~m}$ ), waterfall kayaking and extreme skiing. 
Participation at this level has become highly specialised. Sports such as powerboat racing and stunt plane racing which have also been described as extreme have not been considered because of the low explicit nature component.

The traditional perspective presupposes that participation is about personality structures that mandate participation in risky activities. Participants are assumed to be young, male, and fearless with personality structures that mean they are motivated by thrill and the 'adrenaline buzz' The main personality theories that have been used to define these activities are sensation seeking, Type ' $\mathrm{T}$ ' personality and psychoanalysis. Such theories have led to the adrenaline junkie misnomer that pervades social culture (Barlow, Woodman \& Hardy, 2013). These theories suggest that learning and effective performance is about having, or developing, a personality structure that means a participant thrives because of the danger inherent in the activity.

Recent criticisms of this perspective argue it is overly simplistic and not reflective of the lived experience of participants (Brymer \& Schweitzer, 2013; Brymer, Downey \& Gray, 2009; Brymer, 2009; Brymer \& Oades, 2009). For example, this perspective does not reflect findings that indicate participant experiences of fear and freedom while participating are positive and transformational or that participants often report transcendent qualities intrinsic to the experience (Brymer \& Schweitzer, 2017b). Furthermore, personality research has produced inconsistent findings and has proven limited in its capacity to explain why participation rates are increasing so rapidly (Monasterio \& Brymer, 2015). Critics have also pointed out that an important aspect of extreme or high risk sports, is often overlooked. Namely, that rules are not externally dictated and the environment is not generally artificially constrained. Both these factors might facilitate fast evolution of the sports and emergent possibilities that mean that participation can be taken, literally, to the extreme. The lack of these figurative 
boundaries also suggests a relationship between the performer and the environment that is experienced differently to other sports. The notion of conquering the environment, for instance the expression conquering Everest or battling the elements, used in everyday language, has been critiqued as simplistic and stemming from an inaccurate assessment that assumes sport must be about competition. However, mountains and waves are not aware of any competition against humans. Rather, research examining the relationship between extreme sport participants and nature suggests that participants are most often in harmony with nature, preferring to speak about the experience as immersive and relational (Brymer \& Gray, 2010; Brymer \& Gray 2009; Brymer, Downey \& Gray, 2009)

\section{Adventure sports}

Adventure sports, commonly referred to in a tourism context, have also been associated with risk (Peacock, Brymer, Davids \& Dillon, 2017) and are increasingly the focus of sports coaching research (for example, Collins \& Collins, 2013 2015a, 2015b, 2016.) In the tourism context the range of adventure sports activities has been presented as a continuum (soft - hard) representing degrees of challenge, uncertainty, intensity, duration and perceptions of control (Varley, 2006; Perdomo 2013). Activities include predictable, safe and reliable ones delivered by experienced facilitators with an element of perceived risk but little real risk (commodified adventure, Varley, 2006, see also Loynes 1998 and Brown, 2000) (example activities include, white water rafting, tandem parachuting, and bungy jumping). These commodified adventures contrast with those that require specialised activity and decision making skills, and greater participant commitment and responsibility (Collins\& Collins, 2016, Cloke \& Perkins, 1998). Example activities include white water kayaking, rock climbing, off-piste skiing and mountaineering. From a learning perspective adventure sport participation encompasses 
a broad range of demands; at the commodified end of the continuum the provider offers just enough information for the participant to undertake the activity and achieve what the provider assumes the participant wants from the experience. While at the other, 'authentic' level (Valkonen, Huilaja \& Koikkalainen, 2013), the learning experience focuses on the development of the technical and cognitive skills required to undertake the activity independently of the facilitator (see Collins, Collins \& Grecic, 2015 Christian, Berry \& Kearney, 2017). Nature in these types of activities is seen as a dynamic playground for testing physical and mental resources and possibly providing the thrills and excitement that are deemed to be part of the adventure sport activity. Reflecting the potential breadth of participation, critics point to confusion over assumptions that certain sport or activity types are the same. An emphasis on risk and uncertainty ignores individual differences, the engagement with the culture of a particular adventure sport and role of the environment. In contrast, operators at the commodification end of the continuum most often minimise real risk to ensure safety, while exploiting perceived risk as an important aspect of adventure sport pedagogy. However, by emphasising risk it is possible that organisations are less likely to build long term relationships with participants and are more likely to feel impelled to provide the next thrill seeking activity.

The emphasis on risk is hard to defend and leaves adventure synonymous with the narrow notion of extreme sports (highlighted earlier) and neglects participant lived experience, such as, for example the quest for personal insight, knowledge, spirituality and enlightenment. Research points to a broader experience of nature in adventure sports described as feeling connected to nature (Kerr \& Houge Mackenzie, 2012 and often facilitating a deeper pro-environment identity (Sharma-Brymer, Gray \& Brymer, 2017). 


\section{Action sports}

The term action sport is used to describe a broad category of sports characterised by individuality and differentiated from competitive sports by the lack of rules and regulations (Collins \& Collins, 2016). For example, Rinehart (2000, p.506) defines action sports as 'activities that either ideologically or practically provide alternatives to mainstream sports and mainstream sport values'. Action sports are often considered to be gender neutral and while they can occur on manufactured surfaces (e.g. indoor Climbing, skateboarding in the street) or constructed spaces (e.g. Skateparks) most are still undertaken in the natural world and retain close cultural and performance relationships with the natural world (Van Bottenburg \& Salome, 2010. Examples of nature-based action sports include BMX, kite-surfing, surfing, skydiving, parkour and snowboarding (Booth \& Thorpe, 2007; Wheaton 2004, Thorpe \& Ahmed, 2015). For the most part participants are assumed to be young, (most often generation Y), alternative, and searching for hedonistic outcomes associated, once again, with risktaking. Participants are characterised by having a carefree perspective on life while living outside traditional society norms. Effective performance is measured by how successfully participants can develop the skills to chase increasing levels of performance, thrills, fun and risk. The relationship between action sports, the participant and nature has largely been ignored in the literature.

Critics of this perspective, point out that many participants are not generation $\mathrm{Y}$ and while initial motivations might include hedonism and risk taking the importance of these aspects changes over time. For example, skill development and mastery, competition, aesthetics, and the desire to explore the limits of the body have also been associated with effective performance (Booth \& Thorpe, 2007). Further, research suggests that many action sports might be less dangerous than some traditional sports 
such as rugby, bicycling and swimming (Thorpe, 2016). Equally, action sports have an enormous capacity to bring communities together and facilitate profound personal development (Thorpe, 2016). Critics have also pointed out that many elements of action sports are part of traditional sports such as figure skating, gymnastics and diving. Similarly, to other terms above, the importance of the interaction between participants and their environment has barely been mentioned. For some participants the interaction with the natural world is described as immersive and central to the development of identity and the value of their sport (Young \& Atkinson, 2008).

\section{'Lifestyle' or alternative sports}

Activities typically referred to when discussing lifestyle sports are similar to those discussed as action sports and include skateboarding, windsurfing (and related sports such as kiteboarding), surfing, sailing, alpine skiing, snowboarding, skydiving, and parkour. However, the focus of the lifestyle sports term is socio-cultural. For the most part research on the notion of lifestyle sports has assumed that participation stems from how sports are consumed and the how participants ascribe to particular sub-cultural norms. Often lifestyle sports are delineated by shared practice, dress codes, language and the notion of rebellion. While commercialisation has enforced some regulation in recent years, lifestyle sports are often associated with a perceived lack of rules.

Participants are often assumed to be childless, young, with high educational attainment, and reasonably affluent. Participation is a manifestation of identity and choice rather than the traditional organised structure s associated with competition. From a lifestyle perspective learning is about the development of task oriented skills for participation but also about how easily and effectively a participant embodies the sub-cultural norms. The natural world is rarely acknowledged even though participation in lifestyle sports is frequently undertaken in nature. 
Critiques of this approach point to the myriad opportunities available to the participant and the realisation that just because people undertake a sport does not mean that the sport has to be defined in terms of culture (Brymer 2005). Further, many activities have multiple versions, some of which are competitive and organised similarly to mainstream sport. For example, surfing has an international governing body and is now a competitive sport; climbing is now an Olympic sport and parkour has been recognised as a sport with its own governing body and regulation. The lack of an effective understanding of the importance of nature in lifestyle sports has been critiqued especially as the natural world is so important to many participants that they turn to active conservation (Wheaton, 2007).

In summary, nature sports span a variety of activities. A traditional theoretical perspective links all these sports together by focusing on risk and risk-taking. Critical voices highlight a number of contradictory elements that reflect the assumptions and narrowness of definitions around the participants and their motivations. Nature sports herald from a variety of backgrounds. While in recent years some nature sports might be competitive for some participants, nature sports are different from traditional sports as they are not exclusively competitive and thus not constrained by predetermined rules, regulations and boundaries. For the most part nature sports involve a relationship with the natural environment with subcultural aspects. Despite these critical voices, the risk emphasis has had a profound influence on the design and provision of learning experiences in nature sports.

\section{Learning in nature sports}

Reflecting the traditional, yet criticised, focus on risk designers and facilitators of learning experiences in nature sports typically assume that participants focus on thrills and risk, possibly reflecting the facilitators' own motivation for participation. 
Consequently, risk management has been emphasised and other potential outcomes ignored (Muller \& Cleaver, 2000). This risk focus may reflect an increasingly litigious culture and adds to the perceived pressures from the participants. Initial research and social perception, supported by media and product marketing, has identified and perpetuated the association with risk and risk taking. This infatuation with risk has logically led to, and implicitly justified, a focus on the technical management of risk. Consequently, and justifiably from the risk perspective, training for nature sports facilitators has both explicitly and tacitly prioritised technical risk management above the skills of facilitation. As an example, sixty percent of syllabus content for mountain leader training in the UK relates directly to technical risk management (Collins, Carson, Amos \& Collins, 2017) with less than twenty percent addressing the facilitation (leadership) of the experience. Equally, one of the most often utilised texts for developing leading and facilitating skills in an outdoor education context focuses on risk and risk management (Priest \& Gass, 2005).

Reflecting the explicit risk management content of facilitator training a second, less obvious, aspect of learning design and facilitation has been an emphasis on the task aspects of nature sports. Implicitly, the performance of the activity is also an aspect of risk management. Notably, the teaching of facilitation skills, especially for novice facilitators, focuses on how to teach task and technical skills in a highly formulaic and rigid manner (e.g. www.britishcanoeing.org.uk/courses/level-1-certificate-in-coachingpaddlesport/\#course-content).

A risk focused emphasis has even led to calls to ban certain activities in some places (Brymer and Schweitzer, 2017b; Gauthier, 2009; Mei-Dan, 2013; Monasterio \& MeiDan, 2008) and to restrict certain activities from formal learning experiences (Allman \& Goldenberg, 2012). In the US, National Parks have banned BASE jumping, and 
institutions such as Pennsylvania State University have banned some nature sport clubs arguing that they are too risky (see, www.bbc.co.uk/news/world-us-canada-43899183). One unfortunate consequence of these bans is that participants of certain sports are left with few places or ways to participate unless they undertake their activity illegally (Allman \& Goldenberg. 2012). The bans themselves might be contributing to the notions of sub-cultures, possibly causing accidents and even deaths, which in turn leads to the perspective that nature sports are dangerous and risk focused.

Contemporary research is now identifying a broad and more nuanced range of possible motivations and outcomes ( Asfeldt \& Hvenegaard 2013; Kerr \& Houge Mackenzie, 2012; Stott, Allison, Felter \& Beames 2015; Woodman et al., 2010;, Ryan et al., 2010). In recent years scholars focusing on understanding learning design and facilitation in nature sports have pointed out that while the risk based focus might be appropriate in a learning context for some people some of the time, the need to manage risk in order to optimise the experience for risk seekers and takers is no longer a primary factor. For example, even though the training of mountain leaders is predominantly based on technical risk management, qualified mountain leaders in the UK valued decision making as an aspect of leadership equally to the technical skills associated with risk management (Collins, Carson, Amos \& Collins, 2017). Instead, the design and facilitation of nature sports experiences has been described as a risk versus benefit balance (Collins \& Collins, 2013). From this perspective the poor comprehension of the benefit of a given course of action to the participant has been shown to skew crucial decisions in the learning context. Collins and Collins (2013) argued that perception and management of hazards and the associated risk is highly refined in nature sport facilitators. However, the imbalance between the comprehension of risk and the potential benefits of certain activities and actions in the learning context has contributed 
to a heuristic bias. In turn, this bias has negatively impacted on the decision making processes that drive the management of learning design and facilitation in nature sports. This does not mean that risk management should be overlooked, instead it should be one part of a broader requirement for those designing and facilitating learning experiences as an aspect of risk and benefit decisions. The broader requirement should not only reflect the critical perspectives of the different types of nature sports highlighted above but also, and perhaps most importantly, the lived experience of nature sport participants.

\section{Participant experiences in nature sports: an overview}

Nature sports are varied and diverse (Asfeldt \& Hvenegaard, 2013; Brymer \& Gray, 2009; Kerr \& Mackenzie, 2012; Sibthorp et al., 2007; Stott, Zaitseva, \& Cui, 2012) but the image of the adrenaline junky lingers in the minds of researchers and the general public (Barlow, Woodman, \& Hardy, 2013, Frühauf, Hardy, Pfostl, Hoellen \& Kopp, 2017). One reason that popular imagination and theoretical explanations have emphasised the risk and risk-taking perspective, at the expense of comprehending the benefits, is that conceptual definitions have stemmed from non-participant perspectives and from testing theories developed for unrelated contexts. For the most part participant experiences have been ignored (Brymer \& Schweitzer, 2017a). The lack of shared definitions, classifications or understanding among participants, activity facilitators and researchers has led to convoluted discourse. Consequently, discourse linking nature sports to the design and facilitation of learning experiences is both confusing and contradictory.

This oversimplification is challenged by many authors ( Asfeldt \& Hvenegaard 2013; Kerr \& Houge Mackenzie, 2012; Stott, Allison, Felter \& Beames 2015;) who offer 
nuanced and contemporary perspectives on participation based on the lived experience of participants. For example, Kerr and Mackenzie (2012) present a multidimensional perspective which includes 'pleasurable kinaesthetic bodily sensations from moving in water or air' (p 656). Additionally, Brymer and Gray's (2009) study of veteran extreme sport participants suggests that rather than trying to conquer the environment, participants describe profound engagement and connection with place, people and environment. A growing literature has also made links between nature sports participation and health and wellbeing, conservation, personal development and sustainability motivations. Nature sports have been linked with enhanced communitas amongst participants (e.g. Sharpe 2005; Celsi, 1992), opportunities to develop courage and humility (Brymer \& Oades, 2009, freedom to explore fundamental human values (Brymer \& Schweitzer, 2013), transformational benefits (Brymer \& Schweitzer, 2013) and profound relationships with nature and other participants (Frühauf, Hardy, Pfoestl, Hoellen \& Kopp, 2017).

While individuals seem to seek a variety of seemingly, disparate experiences from their participation in nature sports, we can draw out key common ingredients across different iterations of nature sports. These commonalities can help to refine the conceptual understanding of these activities and provide guidance for those designing and facilitating learning experiences. A participant centred perspective that takes into account a variety of sports undertaken in natural environments suggest that nature sports encompass a number of ingredients: (1) opportunities to connect with and feel part of nature (which often facilitates desires to protect or give back to nature), (2) opportunities to explore human potential, creativity and meaning, (3) opportunities to collaborate and develop communitas, (4) opportunities to explore mastery and development and (5) opportunities to experience enhanced health and well-being. We 
use the analogy of ingredients deliberately as these can be varied to make a range of experiences.

From a learning perspective these ingredients suggest several key notions. Across all types of sports undertaken in natural environments the notion of sporting fields, risk, rules and competition are secondary. Instead, participants emphasise the experience, connection and well-being outcomes. From this perspective, learning facilitation and design needs to provide opportunities for participants to relate to the natural world, to explore human potential and relate effectively with others and the specific nature sport culture. The unconstrained environment is an important part of the learning experience. Rather than seeing this as an element to manage, learning designers could exploit this as the unmanaged environment obliges the participant to learn to adapt in order to interact with that environment in a manner that enables the participant to reach their objectives.

The lack of rules and regulations predetermined by a governing body or association also means that performance is most often determined by collaboration with peers and cultural perspectives that stem from within the grassroots of nature sports. This seems to also encourage evolution, creativity and adaptability while placing equal value on skilful performance and exploration of the potential for a given activity (Immonen et al 2017). Nature sports from this perspective have been identified as ideal mediums for the development of subsidiary aspects such as health, community development and even peace. The nature of the individual's interaction with the physical and social environment reflects the individual's motivation to participate in the activity. From this perspective the learning designer must appreciate that a single size approach does not and cannot fit all participants.

In summary, traditionally there has been a lack of clarity about what defines a nature sport centred around five main issues. Firstly, activities requiring high levels of self- 
knowledge, personal skills, training, commitment, environmental knowledge and task knowledge are assumed to be in the same category as activities that require no previous experience or knowledge of the activity or environment. Secondly, the wide range of motives for participation, such as connection with nature, relieving boredom, pushing personal boundaries, overcoming fear, social relationships, pleasurable kinaesthetic bodily sensations, control, mastery and skill, enhancing well-being and goal achievement has been ignored in favour of a risk perspective. Thirdly, sports differ in terms of activity duration and intensity leading to different interaction effects on behaviour. Fourthly, there is an erroneous assumption that nature sports are synonymous with youth sports or sub-cultures; in fact, participants represent a broad demographic (Frühauf, Hardy, Pfoestl, Hoellen \& Kopp, 2017). Finally, a close look at the history and growth of each sport suggest that rather than being a homogenous group, each has its own unique history, development pattern and focus (Frühauf, Hardy, Pfoestl, Hoellen \& Kopp, 2017). A more nuanced understanding of these activities based on the lived experience of participants provides a richer description of nature sports to guide the design and facilitation of learning experiences. By extension, this will enable facilitators to better meet participant needs and improve the quality of provision.

\section{Facilitating learning in Nature Sports?}

Ewert, Gilbertson, Luo and Voight (2013) suggested that it is incumbent upon adventure recreation providers to offer a range of adventure activities that allow for a complex and diverse set of motivational factors beyond just challenge and risk taking. This advice seems to be relevant for nature sports more broadly. Clearly, this may be achieved by offering a full range of potential experiences to clients via carefully designed programs or experiences. Effective facilitation in nature sports might also 
require a design that contains all ingredients in one activity or experience depending on individual requirements in the group. As such, learning designers and facilitators need to be capable of providing a variety of programs and experiences within each program that will help each learner develop in a manner that suits their needs. From this latter perspective, adaptable and flexible learning designers and facilitators are required. Delivery should be refined by facilitators skilled in meeting the diverse needs and motivations of participants.

A one-size-fits-all approach to facilitation and learning design that focuses on managing risk or assumes that participants take part for thrills and excitement is too simplistic (Brymer \& Renshaw, 2010). For example, an emphasis on task relevant characteristics of nature sports, such as teaching new participants how to manage risks or how to undertake and implement particular technical skills, might be appropriate for some people some of the time but may fail to capitalise on opportunities for immersion or personal development for others. A one-size-fits all approach that assumes participants are a homogenous group of risk-takers from a single background can potentially result in the creation of barriers to learning for many potential participants (Brymer \& Davids, 2012 Brymer \& Renshaw,2010; Brymer 2010). Instead, the facilitator needs to develop adaptability and flexibility underpinned by nuanced judgement and decision making processes (Collins \& Collins, 2015a, 2016) that are dependent on an awareness of individual differences, situational demands (e.g. physical environment, the participants emotional state) (Collins \& Collins, 2015b; 2016; Aaland, Vikene, Varley \& Moe, 2017), and the culture associated with participation in the activity.

The participant's relationship with the physical environment is central to the nature sport experience. Notions of immersion in nature, valuing nature, spirituality, and nature facilitating opportunities for identity development sit alongside desires to conserve and 
protect nature. Exploiting this relationship requires a recognition of it and the provision of opportunities for participants to realise multifaceted outcomes. Participants and facilitators need to understand salient aspects of the specific performance environment well enough to effectively achieve seemingly disparate goals such as recreation and health, for instance. The facilitator might need to design learning experiences that provide opportunities for interactions with environments that facilitate multi-goals within one group. The capacity to recognise individual characteristics, personal goals and opportunities within environments that facilitate those opportunities is important.

Research focusing on cultural intelligence (CI) highlights its significance as a factor in effective leadership and coaching. It appears logical that the facilitator of nature sports experiences would need a cultural sensitivity that reflects the individual participant, the group and the particular nature sport. Consideration of such influences appears pertinent given the culture within nature sports to place a value on seeking out latent potential (e.g., Wiersma, 2014; Ewert, Gilbertson, Luo \& Voight, 2013; Zelenswki \& Nisbet, 2012, Frühauf, Hardy, Pfoestl, Gollen \& Kopp, 2017; Hollett, 2017). Given such diversity and the limitations of a single approach (Collins, Wilmot and Collins,2016), identification of the need for an equally diverse range of approaches to facilitation seems apt. The need for cultural sensitivity and alignment is demonstrated by Objala and Thorpe (2015) who identified that some nature sports participants reject formal highly structured facilitation. While it would be an oversimplification to say all participants reject formal approaches to the design and facilitation of learning (Collins, Wilmot, \& Collins 2016), this does support a need for breadth and range in facilitation skills.

Demonstrating cultural sensitivity that reflects the etiquette and norms of a particular nature sport culture appears imperative. For instance, participants of nature sports are 
increasingly being shown to integrate reflection into their practice as a way of learning (Frühauf A Hardy, Pfoestl, Gollen \& Kopp, 2017; Hollett, 2017). Other studies have identified informal collaborative developmental processes in action sports (Hollett 2017). Such informal collaborative interaction is also observable in adventure sports. Collaboration and reflection within a community of practice appears to exploit a social aspect to nature sports that many authors have identified (Wiersma, 2014; Ewert, Gilbertson, Luo \& Voight, 2013; Zelenswki \& Nisbet, 2012, Frühauf, Hardy, Pfoestl, Gollen \& Kopp, 2017; Hollet, 2017). Within these groups social media and technology forms part of informal facilitation and development (Stozowski \& Collins, 2012; Hollett, 2017). It seems logical that an effective facilitator of nature sports experiences will utilise teaching approaches that draw on the reflective and collaborative aspects that are inherent in the culture of these sports.

Arguably, the most important facilitators are those that introduce nature sports to relative novices. Often this is done by the least experienced facilitators who rely on certified training courses to gain qualifications that allow them to work with groups and individuals. If these courses provide a one-size-fits all approach based on a risk-taking perspective, then naïve soon-to-be facilitators will most likely follow the same route and perpetuate a risk-centric single approach. Courses that focus on teaching facilitators how to help others acquire technical skills or manage risk are in danger of assuming that nature sports participants are a homogenous group intent on risk and risk-taking. Instead, courses that aim to provide learning for facilitators need to focus on providing experiences and environments that develop a well-rounded, adaptable workforce capable of interpreting environmental information and individual requirements in a manner that encourages a relationship between the learner and the environment. Such highly individualised approaches place the participant at the centre of the process. Such 
approaches are, however, time consuming and dependant on facilitators that demonstrate a reflective and metacognitive capacity in addition to technical skills (Collins, Carson, \& Collins, 2016).

Such an approach may have several advantages for the designer, facilitator, and participant. Firstly, the facilitator would be capable of working to deliver a greater range of nature sports experiences. Secondly, a more diverse range of participants can therefore have nature sports experiences. Thirdly, aspects of such training can be designed across several activities, and as such, reduce training repetition across the industry. Fourthly, there would be an improvement in effectiveness and quality of provision.

From this perspective, those studying how best to develop new facilitators might be interested in exploring concepts such as what type of environmental information is relevant for what type of person with what type of goals. Equally, researchers might be interested in exploring how facilitators help learners identify environmental and cultural information.

Clearly, evaluation of the facilitator's capacity to fulfil this new diverse and complex role poses some challenges to the designer and facilitator of learning experiences. As highlighted earlier, assessment of a nature sports facilitator has prioritised and focused on technical skills to manage security. Such assessment can be competency based because the technical skills to assure safety are absolute (black and white), and we would not disagree. Our argument is that the facilitator's role must be beyond just risk management if the full range of participant motivations are to be met and that the assessment of potential leaders should reflect the expertise required (see, Collins, Burke, Martindale \& Cruickshank, 2015). A mixed assessment, in which competencies 
and expertise are evaluated seems more appropriate. Sophisticated roles that require judgment skills would represent a greater proportion of an expertise evaluation.

\section{Conclusion}

Nature sports are a broad array of activities that have historically been associated with risk. Research increasingly recognizes that participants are not driven by risk alone but via a range of sophisticated and nuanced factors. In the past, the training of facilitators of nature sport clearly reflected the emphasis on risk and the demands and perceptions of the activity. In this paper we argue that the comprehension of nature sports has developed and as a result there is a recognition that the nature sports facilitators' role requires a broad range of skills beyond the technical aspects of the activity. .The requirements, training and assessment of the nature sports facilitators should reflect a broader set of practical skills and leadership needs. These processes and outcomes, in turn, require adaptable and flexible facilitators, as 'adaptive' experts (Hatano \& Inagaki, 1986; Tozer, Fazey \& Fazey, 1996) with the skills and breadth of focus to respond to the highly diverse demands of participants. 


\section{References}

Aaland, E., Vikene, O, L., Varley, P., and Moe, V, F. 2017. Situation Awareness in Sea Kayaking: Towards a Practical Checklist. Journal of Adventure Education and Outdoor Learning. 1, no.3: 203-215 Available Via.

http://dx.doi.org/10.1080/14729679.2017.1313169.

Allman, T.L., and Goldenberg, M. 2012. Should extreme sports, such as BASE jumping and other high risk sports, be included in adventure programming?. In Bruce Martin; Mark Wagstaff Eds. Controversial issues in adventure programming, Champaign Ill. : Human Kinetics,

Asfeldt, M., and Hvenegaard, G. 2013. Perceived Learning, Critical Elements and Lasting Impacts on University-based Wilderness Educational Expeditions. Journal of Adventure Education and Outdoor Learning, 14, no.2: 132-152. Available Via. http://doi.org/10.1080/14729679.2013.789350.

Barlow, M., Woodman, T., and Hardy, L. 2013. Great Expectations: Different High-risk Activities Satisfy Different Motives. Journal of Personality and Social Psychology, 105, no.3: 458-475 Barlow, M., Woodman, T., Chapman, C., Milton, M., Stone, D., Dodds, T., and Allen, B. 2015. Who Takes Risks in High-risk Sport? The Role of Alexithymia. Journal of Sport \& Exercise Psychology 37: 83-96. Available Via. doi: 10.1123/jsep.2014-0130.

Booth, D., and Thorpe, H. 2007. The Meaning of Extreme. In D. Booth and H. Thorpe. eds. The Berkshire Encyclopaedia of Extreme Sports. Great Barrington: Berkshire. 181197.

Brown, H. 2000. Passengers, Participants, Partners and Practitioners. Working with Risk to Empower Groups. Horizon, no. 12: 37-39.

Brymer, E. 2010. Skill Development in Canoeing and Kayaking: An Individualised Approach. In Renshaw, I., Davids, K., and Savelsbergh, G. eds. 2010. Motor Learning in Practice: A constraints-led Approach. London: Routledge. 152-160.

Brymer, E., Downey, G., and Gray, T. 2009. Extreme Sports as a Precursor to Environmental Sustainability. Journal of Sport \& Tourism 14, no. 2-3: 193-204.

Brymer, E., and Davids, K. 2014. Experiential Learning as a Constraints-led Process: An Ecological Dynamics Perspective. Journal of Adventure Education and Outdoor Learning 14, no. 2: 103-117.

Brymer, E., and Schweitzer, R. 2017a. Phenomenology and the Extreme Sports Experience. Routledge.

Brymer, E., and Schweitzer, R. D. 2017b. Evoking the Ineffable: The Phenomenology of Extreme Sports, Psychology of Consciousness: Theory, Research, and Practice. 4, no. 1: 63-74Brymer, E, 2005. Extreme dude! A phenomenological perspective on the extreme sport experience, $\mathrm{PhD}$ thesis, University of Wollongong. 
Brymer, E. 2005. Extreme dude! A phenomenological perspective on the extreme sports experience. $\mathrm{PhD}$ Thesis. Available Via

https://ro.uow.edu.au/cgi/viewcontent.cgi?referer=https://www.google.co.uk/\&httpsredi $\mathrm{r}=1 \&$ article $=1379 \&$ context $=$ theses

Brymer, E. 2009. Extreme Sports as a Facilitator of Ecocentricity and Positive Life Changes. World Leisure Journal 51, no. 1: 47-53.

Brymer, E. 2010. Risk and Extreme Sports: A Phenomenological Perspective. Annals of Leisure Research 13, no. 1-2: 218-239.

Brymer, E., and Gray, T. 2010. Developing an Intimate "Relationship" with Nature Through Extreme Sports Participation. Leisure/Loisir 34, no. 4: 361-374.

Brymer, E., and Davids, K. 2012. Ecological Psychology as a Theoretical Framework for Development of Sustainable Behaviours Towards the Environment. Journal of Environmental Education Research.

Brymer, E., and Oades, L. 2009. Extreme Sports: A Positive Transformation in Courage and Humility. Journal of Humanistic Psychology 49, no. 1: 114-126. Available Via. http://dx.doi.org/10.1177/0022167808326199

Brymer, E., and Renshaw, I. 2010. An Introduction to the Constraints-led Approach to Learning in Outdoor Education. Australian Journal of Outdoor Education 14, no. 2: 33 41.

Brymer, E., and Schweitzer, R. 2013. Extreme Sports are Good for Your Health: A Phenomenological Understanding of Fear and Anxiety in Extreme Sport. Journal of Health Psychology 18, no. 4:477-87.

Brymer, E., and Gray, T. 2009. Dancing with Nature: Rhythm and Harmony in Extreme Sport Participation. Journal of Adventure Education and Outdoor Learning 9, no. 2: 135-149. Available Via. http://doi.org/10.1080/14729670903116912.

Celsi, R, L. 1992. Transcendent Benefits of High-Risk Sports. In NA - Advances in Consumer Research Volume 19. John, F., Sherry, Jr., and Brian Sternthal. eds. Provo, UT: Association for Consumer Research. 636-641.

Christian, E., Berry, M., and Kearney, P. 2017. The Identity, Epistemology and Developmental Experiences of High-level Adventure Sports Coaches. Available Via. http://dx.doi.org/10.1080/14729679.2017.1341326.

Cloke, and Perkins. 1998. Cracking the Canyon with the Awesome Foursome: Representations of Adventure Tourism in New Zealand.

Collins, D., Burke, V., Martindale, A., and Cruickshank, A. 2015.The Illusion of Competency Versus the Desirability of Expertise: Seeking a Common Standard for Support Professions in Sport. Sports Med 45:1-7. Available Via. doi 10.1007/s40279014-0251-1.

Collins, D., Wilmot, T., and Collins. L. 2016. Over Egging the Pudding? Comments on Ojala and Thorpe. International Sports Coaching Journal. Available Via. doi: 10.1123/iscj.2015-0068. 
Collins, L., and Collins, D. 2013. Decision Making and Risk Management in Adventure Sports Coaching. Quest 65, no. 1: 72-82. Available Via.

http://doi.org/10.1080/00336297.2012.727373.

Collins, L., and Collins, D. 2015a. Integration of Professional Judgement and Decisionmaking in High-level Adventure Sports Coaching Practice. Journal of Sports Sciences 33, no. 6: 622-633. Available Via. http://doi.org/10.1080/02640414.2014.953980.

Collins, L., and Collins, D. 2015b. Professional Judgement and Decision-making in Adventure Sports Coaching: the Role of Interaction. Journal of Sports Sciences, no. 112. Available Via. http://doi.org/10.1080/02640414.2014.953980.

Collins, L., and Collins, D. 2016. Challenges in Adventures Sports Coaching. In Routledge International Handbook of Outdoor Studies. Available Via. http://doi.org/10.4324/9781315768465.ch44.

Collins, L., Carson, H. J., Amos, P, and Collins, D.2017. Examining the Perceived Value of Professional Judgment and Decision Making in Mountain Leaders in the UK: A Mixed-Methods Investigation. Journal of Adventure Education and Outdoor Learning. Available Via. doi.org/10.1080/14729679.2017.1378584.

Collins, L., Carson, H.J., and Collins, D. (2016) Metacognition and professional judgment and decision making: Importance, application and evaluation. International Sport Coaching Journal, Available Via. http://doi.org/10.1123/iscj.2016-0037

Collins, L., Collins, D, and Grecic, D. 2015. The Epistemological Chain in high level Adventure sports coaches. Journal of Adventure Education and Outdoor Learning. Available Via. doi.org/10.1080/14729679.2014.950592

Crum, B. J. 1991. 'Sportification' of Society and Internal Sports Differentiation. Spelen Sport, no. 1, 2-7.

Ewert A., Gilbertson K., Luo Y., Voight A. 2013. Beyond "because it's there": Motivations for pursuing adventure recreational activities. Journal of Leisure Research, no. 44, 91-111.

Frühauf A, Hardy W, Pfoestl D, Hoellen FG and Kopp M (2017). A qualitative approach on motives and aspects of risks in freeriding . Front. Psychology, no. 8:1998. doi: 10.3389/fpsyg.2017.01998netics.

Hatano, G., \& Inagaki, K. (1986). Two courses of expertise. In H. Stevenson, H. Azuma, \& K.

Howlett, T. 2017. Symbiotic Learning Partnerships in Youth Action Sports: Vibing, Rhythm, and Analytic Cycles Convergence. The International Journal of Research into New Media Technologies. Available Via. https://dx.doi.org/10.22318/cscl2017.88

Immonen, T., Brymer, E,. Orth, D., Davids, K., Felletti, F., Liukkonen, J. and Jaakkola, T .2017. Understanding Action and Adventure Sports Participation-An Ecological Dynamics Perspective. Sports Med Open. doi: 10.1186/s40798-017-0084-1 
Kerr, J. H., and Houge Mackenzie, S. 2012. Multiple Motives for Participating in Adventure Sports. Psychology of Sport and Exercise 13, no. 5: 649-657. Available Via. http://doi.org/10.1016/j.psychsport.2012.04.002.

Krien, K. J. 2014. Nature Sports. Journal of Philosophy in Sport 41, no. 2: 193-208. Available Via. doi: 10.1080/00948705.2013.785417.

Loynes, C. 1998. Adventure in a Bun. Journal of Experiential Education 21, no. 1: 3539.

Melo, R., and Gomes, R. 2017. A Sociocultural Approach to Understanding the Development of Nature Sports. In R. Melo and C. Sobry. coords. 2017. Sport Tourism: New Challenges in a Globalized World: 47-76. Newcastle: Cambridge Scholars Publishing.

Monasterio, E. and Brymer, E. 2015. Mountaineering Personality and Risk. In G. Musa, J. Higham, A. Thompson- Carr. eds. Mountaineering Tourism. Routledge.

Muller, T., and Cleaver, M. 2000. Targeting the CANZUS Baby Boomer Explorer and Adventurer Segments. Journal of Vacation Marketing.

Objala, A. L., and Thorpe, H. 2015. The Role of the Coach in Action Sports: Using a Problem-based Learning Approach. International Sport Coaching Journal, no. 2: 64-71. Available Via. doi:10.1123/ iscj.2014-0096.

Peacock, S., Brymer, E., Davids, K., \& Dillon, M. (2017) An ecological dynamics perspective on adventure tourism. Tourism Review International, 21, (3), 307-316

Perdomo, Y. 2013. Global Report on Adventure Tourism. Available Via. http://doi.org/10.1017/CBO9781107415324.004.

Pine, J., and Gilmore, J. H. 1998. Welcome to the experience. Harvard Business Review 76, no. 4: 97-105. Available Via. http://doi.org/Article.

Priest, S., and Gass, M. A. 2005. Effective Leadership in Adventure Programming. Human Kinetics

Rinehart, R. 2005. “BABES” \& BOARDS: Opportunities in new millennium sport? Journal of Sport \& Social Issues, 29, 232-255. Avaialble Via.https://doi.org/10.1177/0193723505277909

Rossi, B., and Cereatti, L. 1993. The Sensation Seeking in Mountain Athletes as Assessed by Zuckerman's Sensation Seeking Scale. International Journal of Sport Psychology, no. 24: 417-431.

Ryan, R. M., Weinstein, N., Bernstein, J., Brown, K. W., Mistretta, L., and Gagné, M. 2010. Vitalizing Effects of Being Outdoors and in Nature. Journal of Environmental Psychology, no. 30: 159-168. Available Via. doi: 10.1016/j.jenvp.2009.10.009.

Self, D. R., Henry, E. D. V., Findley, C. S., and Reilly, E. 2007. Thrill Seeking: The Type T Personality and Extreme Sports. International Journal of Sport Management and Marketing 2, no. 1-2: 175. Available Via. http://doi.org/10.1504/IJSMM.2007.011397. 
Sharma-Brymer, V., Gray, T., and Brymer, E. 2017. Sport Participation to Create a Deeper Environmental Identity with Pro-environmental Behaviors. In McCullough, B. P., and Kellison, T. B. eds. Routledge Handbook on Sport, Sustainability and the Environment. New York: Routledge.

Sharpe, E. K. 2005. Delivering Communities: Wilderness Adventure and the Making of Community. Journal of Leisure Research 37, no. 3:255-280.

Sibthorp, J., Paisley, K., and Gookin, J. 2007. Exploring Participant Development Through Adventure-Based Programming: A Model from the National Outdoor Leadership School. Leisure Sciences 29, no. 1: 1-18. Available Via. http://doi.org/10.1080/01490400600851346.

Slanger, E., and Rudestam, K. E. 1997. Motivation and Disinhibition in High Risk Sports: Sensation Seeking and Self-efficacy. Journal of Research in Personality, no. 31: 355-374.

Stott, T., Allison, P., Felter, J., and Beames, S. 2015. Personal Development on Youth Expeditions: A Literature Review and Thematic Analysis. Leisure Studies 34, no. 2 : 197-229. Available Via. http://doi.org/10.1080/02614367.2013.841744.

Stott, T., Zaitseva, E., and Cui, V. 2012. Stepping Back to Move Forward? Exploring Outdoor Education Students' Fresher and Graduate Identities and Their Impact on Employment Destinations. Studies in Higher Education, (February 2013): 1-23. Available Via. http://doi.org/10.1080/03075079.2012.743116.

Stozkowski, J., and Collins, D. 2012. Communities of Practice, Social Learning and networks:exploiting the social side of coach development. Sport, Education and society. no. 6: 773-788

Thorpe, H. 2016. Action Sports for Youth Development: Critical Insights for the SDP Community. International Journal of Sports policy and politics. no 8, 91-116.

Thorpe, H. and Ahamed, N. 2015. Youth Action Sports and Political Agency in the Middle East: Lesson from a Grassroots Parkour Group Gaza. International Review for the Sociology of Sport. Available Via. doi: 19.1177/1012690213490521.

Tozer, M., Fazey, I. \& Fazey, J. 2007. Recognizing and developing adaptive expertise within outdoor and expedition leaders, Journal of Adventure Education and Outdoor Learning, 7:1, 55-75, DOI: 10.1080/14729670701349780

Valkonen, J., Huilaja, H. and Koikkalainen, S. 2013. Looking for the Right Kind of Person: Recruitment in Nature Tourism Guiding Scandinavian. Journal of Hospitality and Tourism. no 3, 228-241

Van Bottenburg, M., and Salome, L. 2010. The Indoorisation of Outdoor Sports: An Exploration of the Rise of Lifestyle Sports in Artificial Settings. Leisure Studies 29, no. 2: 143-160. Available Via. doi: 10.1080/02614360903261479.

Varley, P. 2006. Confecting Adventure and Playing with Meaning: The Adventure Commodification Continuum. Journal of Sport and Tourism 11, no. 2: 173-194. Available Via. http://doi.org/10.1080/14775080601155217. 
Wiersma, L.D. 2014 A Phenomenological Investigation of the Psychology of Big-Wave Surfing at Maverick's Volume: The Sport Psychologist, no. 28, 151-163

Wheaton, B. 2004. Understanding Lifestyle Sports: Consumption, Identity and Difference. Routeledge

Wheaton, B. 2007. Identity, Politics, and the Beach: Environmental Activism in Surfers Against Sewage. Leisure Studies, 26, no.3: 279-302. Available Via. doi.org/10.1080/02614360601053533.

Woodman, T., Hardy, L., Barlow, M., and Le Scanff, C. 2010. Motives for Participation in Prolonged Engagement High-risk Sports. An Agentic Emotion Regulation Perspective. Psychology of Sport and Exercise 11: 345-352. Available Via. doi: 10.1016/j.psychsport.2010.04.002.

Young, K., and Atkinson, M. 2008. Tribal Play: Subcultural Journeys Through Sport. 4th edition. JAI Press.

Zelenski, J,M. and Nisbet, E. K. 2012. Happiness and Feeling Connected: The Distinct Role of Nature Relatedness. Environment and Behavior, 46, no.1: 3-23

doi.org/10.1177/0013916512451901 